\title{
Fishing disturbance and marine biodiversity: role of habitat structure in simple soft-sediment systems
}

\author{
Simon F. Thrush ${ }^{1, *}$, Judi E. Hewitt ${ }^{1}$, Greig A. Funnell ${ }^{1}$, Vonda J. Cummings ${ }^{1}$, \\ Joanne Ellis ${ }^{1}$, Diane Schultz ${ }^{1}$, Drew Talley ${ }^{2}$, Alf Norkko ${ }^{1}$ \\ ${ }^{1}$ National Institute of Water and Atmospheric Research, PO Box 11-115, Hamilton, New Zealand \\ ${ }^{2}$ Scripps Institution of Oceanography, University of California San Diego, La Jolla, California 92093-0201, USA
}

\begin{abstract}
Broad-scale anthropogenic disturbances that reduce the density of epifauna and homogenise surficial sediments can have important consequences for seafloor biodiversity. We investigated the habitat structure and macrofaunal diversity of relatively simple soft-sediment habitats over a number of spatial scales ( $\mathrm{cm}$ to $\mathrm{km}$ ) to identify the role of habitat structure in influencing macrobenthic diversity and to assess the validity of using habitat structure as a surrogate measure for biodiversity. We sampled 10 locations with differences in habitat structure using a sampling design that nested macrobenthic core samples within videoed transects of the seafloor. This allowed us to determine relationships between observable habitat structure and macrobenthic diversity at a number of spatial scales. We characterised elements of habitat structure based on direct counts of surficial sediment characteristics and the presence of other immobile features, many of which were biogenic in origin. We also used multivariate measures (the relative multivariate dispersion, the mean and range of the Bray-Curtis dissimilarity along the transects) to characterise habitat structure at the transect scale. We developed regression models based on measures of habitat structure that explained 74 to $86 \%$ of the variance in macrobenthic diversity. This result suggests that removal of habitat structure in relatively low-structure soft-sediment systems will significantly decrease their biodiversity, and consequently that of the wider marine ecosystem.
\end{abstract}

KEY WORDS: Biodiversity · Soft-sediments · Habitat structure $\cdot$ Habitat heterogeneity $\cdot$ Habitat complexity $\cdot$ Habitat disturbance $\cdot$ Fishing impacts $\cdot$ Nested multi-resolution sampling $\cdot$ Kawau Bay • New Zealand

Resale or republication not permitted without written consent of the publisher

\section{INTRODUCTION}

Habitat disturbance by trawling and dredging is probably one of the most significant threats to marine benthic biodiversity (Hammer \& Jansson 1993, Norse 1993, Dayton et al. 1995, 1998, Jennings \& Kaiser 1998, Thrush et al. 1998, Auster \& Langton 1999). While some fisheries are targeted in areas of highly structured habitat (e.g., Cranfield et al. 1999, Koenig et al. 2000), most of the seafloor is soft-sediment habitat. These soft-sediment habitats are not generally consid-

*E-mail: s.thrush@niwa.cri.nz ered highly structured habitats, although they can support high diversity (Etter \& Grassle 1992, Coleman et al. 1997, Gray et al. 1997, Snelgrove 1999). Given the intrinsic and extrinsic value of marine biodiversity (e.g., Bengtsson et al. 1997, Costanza et al. 1997, Freckman et al. 1997, Gray 1997, Schlapfer \& Schmid 1999), there is an increasing need for resource managers to sustain, maintain or enhance biodiversity under national or international laws or agreements (e.g., United Nations Environment Programme 1992, Fisheries Act 1996). There are a number of habitat management options aimed at reducing the threat to marine biodiversity, ranging from the creation of marine protected areas through the spatial and tempo- 
ral management of areas of the seafloor, to gear limitation or modification. These options have common elements of reducing habitat disturbance and actively managing the seafloor. Justifying the need for and testing the efficacy of habitat management will require the collection of data to rigorously define the biodiversity of a habitat and assess responses to disturbance. This presents 3 problems: (1) methods of sampling potentially large areas of the seabed cost-effectively to directly or indirectly estimate biodiversity need to be developed; (2) traditional macrobenthic sampling techniques (e.g., cores or grabs) are not always appropriate for collecting the information on biogenic and physical structures needed to define benthic habitats; (3) aspects of the seafloor habitat most related to biodiversity need defining. To reach general conclusions about the relationship between habitat structure and biodiversity, we need to assess relationships across sampling scales and define operational measures that treat habitat structure as landscape elements characterised by variations in patch density, size and spatial arrangement.

Biodiversity is often considered to be positively associated with habitat complexity or heterogeneity (Tokeshi 1999). There are problems with the definition of these terms (see Kolasa \& Rollo 1991, McCoy \& Bell 1991). For example, McCoy \& Bell (1991) define habitat heterogeneity as the variation in relative abundance of different structural components, while complexity is defined as the absolute abundance of individual components. However, other terminology and definitions are common (Bell et al. 1991). In this paper, we use sampling and analytical procedures that combine elements of both heterogeneity and complexity as defined by McCoy \& Bell (1991), and we refer to habitat structure as a term encompassing the variety, abundance and spatial arrangement of a variety of physical and biological processes.

Soft-sediment habitats are often considered to have low topographic structure. Perception of habitat structure is of course scale-dependent, but complex seafloor habitats are generally thought of as distinct features such as reefs, kelp forests or seagrass beds, despite the fact that organisms that modify the 3-dimensional structure above and below the sediment surface are widely distributed and can affect benthic community structure (e.g., Rhoads et al. 1977, Reise 1981, van Blaricom 1982, Woodin 1983, Luckenbach 1987, Dame 1993, Graf \& Rosenberg 1997, Green et al. 1998).

Studies that merely contrast simple and highly structured habitats are of limited value in defining general relationships between habitat structure and diversity. Firstly, the importance of these processes will be dependent on the spatial and temporal scales of observation or sampling (Dayton \& Tegner 1984, Schneider et al. 1987, Thrush et al. 1997b). For example, Blanchard \& Bourget (1999) related various aspects of physical heterogeneity of a rocky-shore coastline measured at multiple spatial scales to aspects of benthic community structure (including diversity) and showed that processes operating over different spatial scales best explained different aspects of community structure. Macrobenthic diversity was best explained at intermediate scales (100s of metres), although effects cascaded across scales. Secondly, operational measures of habitat heterogeneity, complexity and structure are needed that include the quantification of a variety of different elements. Many studies categorise habitats into 'simple' or 'structured' based on the presence of a single feature rather than treating them as landscape elements (for examples of the latter see Robbins \& Bell 1994, Irlandi et al. 1995, Thrush et al. 1997a). The problem of over-generalizing results is especially relevant to any general consideration of biodiversity (Huston 1997). Thus to reach general conclusions on the influence of habitat structure on biodiversity, it is important to assess the role of a variety of features, not just variation in a single element of habitat structure.

In this study, our goal was to estimate the relationship between habitat structure and macrobenthic diversity in a coastal environment contrasting a variety of soft-sediment habitats. We employed a novel, nested sampling design that links macrobenthic core samples to video transects. This allowed us to sample at multiple spatial scales, detecting locally important elements of habitat structure while also extending the generality of the survey by encompassing a variety of habitats. Our sampling strategy was not designed to fully characterise macrobenthic diversity within a site, but rather to enable us, with minimal cost and effort, to make comparisons between sites while still including high levels of variation in habitat structure within sites. We tested the prediction that across sites there would be a positive relationship between habitat structure and macrobenthic diversity, and that this relationship resulted from different aspects of habitat structure occurring at different scales. This sampling design also enabled us to assess the utility of using seafloor video images as a surrogate measure for macrobenthic diversity.

\section{METHODS}

Site description and sampling. Sites were located in the vicinity of Kawau Bay $\left(36^{\circ} 24^{\prime} \mathrm{S}, 174^{\circ} 48^{\prime} \mathrm{E}\right)$ a large, 10 to $20 \mathrm{~m}$ deep, embayment on the north-east coast of North Island, New Zealand (Fig. 1). Kawau Bay is composed mainly of soft-sediment habitats that vary in both sediment characteristics and biogenic structure. 
Sites were chosen to reflect this habitat variation and to encompass a range of geographic locations around the bay. In total, 10 sites were sampled between 18 and 25 February 1999.

Sampling involved the collection of variable numbers of core samples at each site following the sampling design of Hewitt et al. (unpubl. data). When sampling to assess diversity, it is desirable to encompass as much variation as possible by sampling many different sites and taking multiple samples to assess variation within sites. Inevitably the need to collect many samples at many locations must be balanced against cost/effort constraints. The sampling strategy developed by Hewitt et al. (unpubl. data) maximises the variability encompassed along a transect while minimising the number of core samples collected. It involves nesting core samples within videoed transects of the seafloor, thus allowing analysis of relationships between observed habitat structure and macrobenthic diversity at a number of spatial scales.

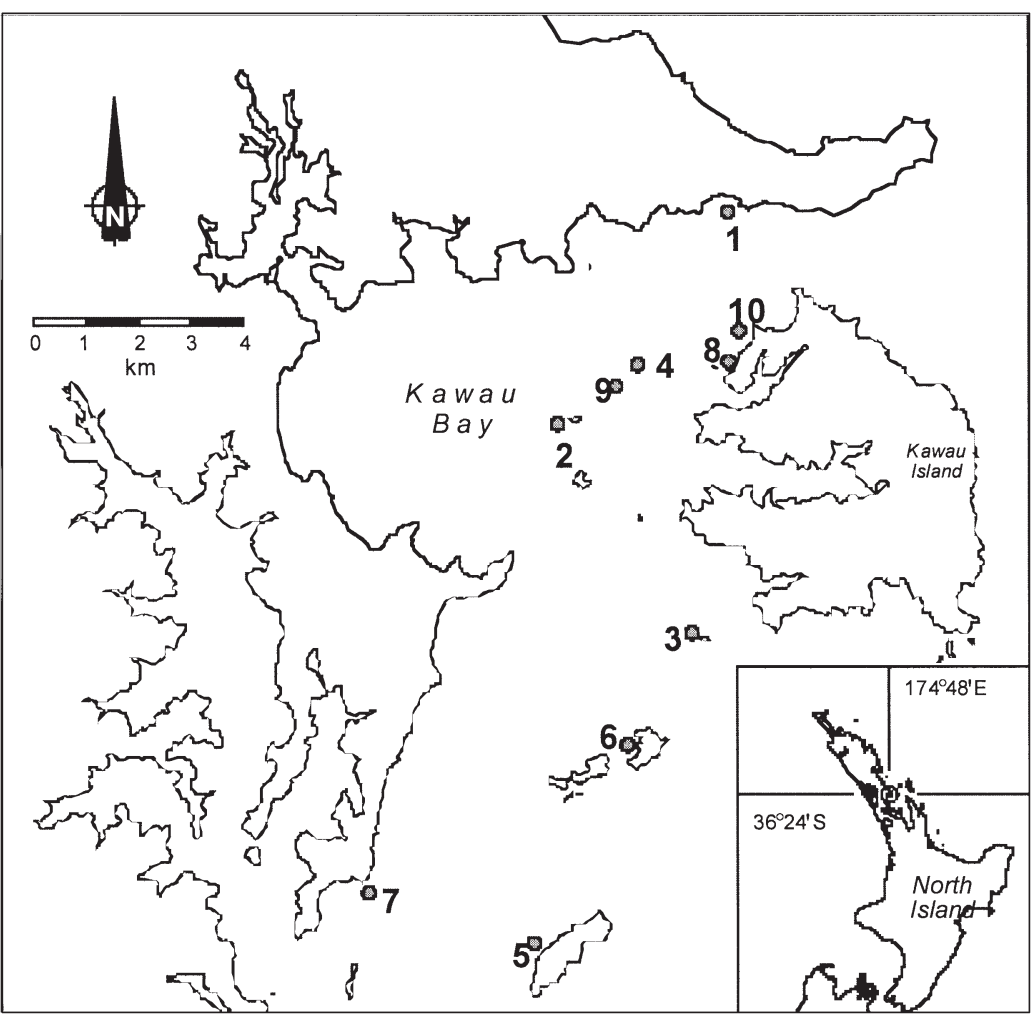

Fig. 1. Location of the 10 sampling sites in Kawau Bay, North Island, New Zealand

Within each site, 2 locations were haphazardly chosen. At each location a pair of $20 \mathrm{~m}$ transects were deployed. The 2 transects were laid on the seafloor at right angles to each other. One transect in each pair was always aligned with the tidal flow (typically northsouth). As each transect rope was laid out, the diver observed variations in habitat features. Habitat structural elements included the presence of large bivalves, sponges, hydroids, and surficial sediment characteristics (e.g., shell hash, sand, mud). Corers $(10 \mathrm{~cm}$ diameter, $12 \mathrm{~cm}$ deep) were then positioned along the transect to record the apparent variation in habitat structure at the $20 \mathrm{~m}$ scale. A maximum of 5 cores were collected along each transect, depending on the habitat variability observed: where the sediment structure appeared homogeneous down the length of the transect, 1 core was taken at the start and end of a transect. We focused on sampling in and out of large patches ( $<4 \mathrm{~m}$ diameter) or near and away from individual features (e.g., sponges) down the transect. The sampling programme was not intended to provide detailed information on small-scale density variation that would be encompassed by contiguous sampling. After corers had been inserted into the sediment, the transect was videoed using a digital video camera with the lens held perpendicular to the seafloor at $0.7 \mathrm{~m}$ above the seabed

(width of video transect $=80 \mathrm{~cm}$ ). Corers were premarked so that they could be individually identified on the videotape. After the corers and transect had been videoed, core samples were collected and taken to the surface.

Core samples were sieved (500 $\mu \mathrm{m}$ mesh), and then preserved in $70 \%$ isopropanol and $0.1 \%$ Rose Bengal in seawater. In the laboratory, macrofauna were sorted, and identified to the genus level (with the exception of syllid polychaetes which were identified as either Syllinae and Exogoninae).

Visual classification of video images. For visual classification, a composite strip $100 \mathrm{~cm}$ long centred on each corer was assembled from 2 to 4 individual video frames, using a frame grabber (Sony DVBK 2000E Version 1.00). Pixel resolution was $1.7 \mathrm{~mm}$. Grids of $30 \times 30,30 \times 60$, and $30 \times 100 \mathrm{~cm}$ were overlaid on the grabbed strip (again centred on the core) to provide a measure of the number of different habitat features represented at each spatial scale. Habitat features were counted where they intersected with nodes of the grid (5 cm line spacing) and were assigned to 1 of 4 different categories of habitat structure (see Table 1). Habitat structure measures (based on the number of different habitat features observed) were then calculated for each of the 3 spatial sam- 
pling grains (i.e., $30 \times 30,30 \times 60$, and $30 \times 100 \mathrm{~cm}$ ) surrounding each core.

Statistical analysis. A number of diversity indices were calculated using the PRIMER software package (Clarke 1993). We used the number of genera per core, Margalef's richness ( $d=$ number of genera -1$)$ / $\log$ number of individuals; Shannon-Wiener diversity $H^{\prime}=-\Sigma\left(P_{i} \times \log \left(P_{i}\right)\right)$, where $P_{i}=$ the proportion of the total sample belonging to the $i$ th genus; and Pielou's evenness $\left(J^{\prime}=H^{\prime} / \log\right.$ number of genus). These indices are common measures of diversity (Hill 1973, Peet 1975, Pielou 1975, Krebs 1989) and, by using a number of indices, we included a variety of information about diversity beyond merely the number of taxa. Gray (2000) pointed out the substantive confusion in the application of various measures of species diversity and the scales at which they are applied. In this paper we describe sample (within-site) diversity and determine the strength of relationships between these indices and measures of habitat structure at this scale.

Preliminary analysis indicated interactions between the different elements of habitat structure and the sampling grains over which they were influencing macrobenthic diversity. Thus, we determined the relationship between habitat structure reflected by visual counts from video images for each of the 3 spatial grains (i.e., $30 \times 30,30 \times 60$, and $30 \times 100 \mathrm{~cm}$ ).

We used direct counts of the habitat features categorised in Table 1. Mobile biological features were not included in our analysis, because we could not be sure how long those elements were resident over the sediments sampled. The basic measures of variation in habitat structure in the vicinity of macrofaunal core samples provided an incomplete picture of variation in habitat structure, as the habitat features can change along the length of the transect (e.g., a shift from sponges to shell hash). To overcome this problem, we also used multivariate approaches to define the average and range of variation in habitat structure along transects within each site. The multivariate measures were the relative multivariate dispersion, the mean Bray-Curtis dissimilarity between habitat structure variables, and the range of Bray-Curtis dissimilarities. These variables were calculated using PRIMER. High relative multivariate dispersion values indicate a high number of different habitat elements within a site (see Warwick \& Clarke [1993] for discussion of relative multivariate dispersion). High mean Bray-Curtis dissimilarity reflects a site containing a number of dissimilar habitats.

Kruskal-Wallis tests were used to test for overall differences between sites in both macrobenthic diversity and habitat structure. When tests were significant ( $\mathrm{p}=$ $\leq$ 0.05), Tukey's rank-sum multiple-comparison test was used to identify sites or groups of sites that were significantly different from the others (Zar 1984).

Exploring relationships between habitat structure and macrobenthic diversity. Mean values of the different measures of macrobenthic diversity were calculated for each site and regressed (Model 1) against all the measures of habitat structure and water depth averaged across transects at each site. To develop regression models we used backwards variable selection with an exit level of $\mathrm{p}=0.15$. Variables were dropped from the model only if their removal did not markedly affect the adjusted $r^{2}$ (McCullagh \& Nelder 1989, Crawley 1993). The first variables removed were the different sample grains used to characterise habitat structure. Regression models were constrained to only

Table 1. Elements of habitat structure assigned to different categories

\begin{tabular}{|llll|}
\hline Immobile biological features & Mobile biological features & Sediment characteristics & Miscellaneous \\
\hline Ascidians & Drift weed & Boulder (256 to 4096 mm) & Sand ripples \\
Coralline algae & Gastropod: Cominella sp. & Cobble (64 to 256 mm) & Ray pits \\
Chaetopterid tubes & Hermit crabs: Paguristies sp. & Gravel (2 to 4 mm) & Shells \\
Diatom mat & Pseudofaeces & Sand & Shell hash \\
Horse mussels (live Atrina zelandica) & Starfish: Asteropecten sp., & Sandy mud & Horse mussel shells \\
& Cosinasteris sp., Asterina sp. & & lying flat \\
Holes/burrows & Sea cucumbers: Stichopus mollis & Muddy sand & upright and dead \\
Hydroids & Ophiuroids & Mud & Scallop shells \\
Mounds & & & Dead sponge \\
Scallops Pecten novaezelandiae) & & & \\
Sponges & & & \\
Seaweed & & & \\
Spionid worm tube mat & & & \\
\hline
\end{tabular}


maximally include 1 sample grain for each variable. After finding the most parsimonious model, a number of different orders of dropping variables were tried to determine if the sample grains chosen produced the best and most consistent model.

To investigate how well the multivariate pattern exhibited by the macrobenthic core data reflected the multivariate pattern of habitat structure elements derived from the video data, we used the RELATE routine within PRIMER (Clarke \& Warwick 1994). This is a Procrustes-type analysis (see Gower 1987, Legendre \& Legendre 1998) except that whereas Procrustes analysis depends on dimensionality, here the fundamental constructs are the similarity matrices and they are compared by the Spearman rank-correlation coefficient. Comparison of multivariate data structure was based on genus-level presence/absence core data and Euclidean distance matrix of the presence/absence of all habitat structure elements (except mobile biological features) found in video data at the largest grain sampled $(30 \times 100 \mathrm{~cm})$. Due to software limitations, the data set was split in half, and the 2 transect directions (north-south and east-west) were tested separately.

\section{RESULTS}

\section{Variation in habitat structure and macrobenthic diversity measures between sites}

Macrobenthic diversity and habitat structure varied significantly between sites (Fig. 2, Table 2). KruskalWallis and associated multiple-comparison tests revealed variation in the rank order of sites for each diversity measure. However, sites grouped as either highest or lowest diversity were similar. Univariate measures of habitat structure based on immobile biological features, sediment particle characteristics and miscellaneous features all showed differences amongst sites. The order of sites varied for the different habitat structure elements, indicating different combinations of habitat features across sites (Fig. 2). Although 3 different sample grains were initially used in the analysis, Table 2 presents results only for those grains finally selected for use in the regression modelling. We included this multi-scale aspect in the analysis as we expected habitat structure to vary with scale and potentially reflect differences in the strength and
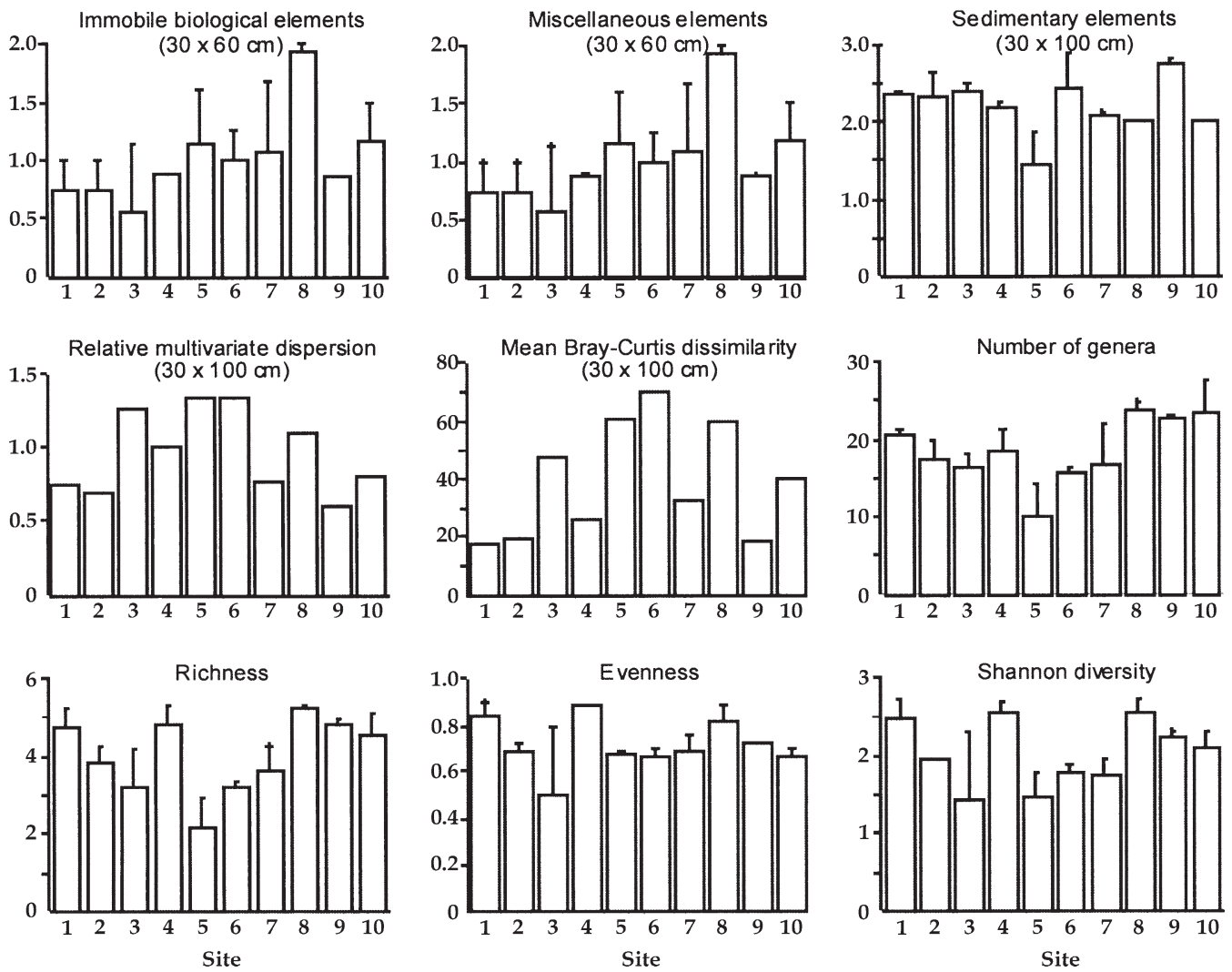

Fig. 2. Variation in habitat structure elements and macrobenthic diversity between sites. For habitat structure elements the sample grain is presented in parentheses. Only the sampling grain finally selected for use in the regression modelling is presented. Results for $30 \times 30 \mathrm{~cm}$ are not presented as this was not the most important grain. All values are mean (+SE), except for the multivariate measures (relative multivariate dispersion and mean Bray-Curtis dissimilarity), which are simply value per site 
Table 2. Site differences in macrobenthic diversity and habitat structure. p values derived from Kruskal-Wallis tests; sites connected by lines are not significantly different from each other (Tukey's test). Sites are ordered (left-to-right) from highest to lowest mean values. Site average minimum and maximum values are also presented for each variable. Data are presented only for those size categories selected for regression modelling

\begin{tabular}{|c|c|c|c|c|c|c|c|c|}
\hline \multicolumn{4}{|c|}{ Macrobenthic diversity } & \multicolumn{5}{|c|}{ - Habitat structure } \\
\hline & $\mathrm{p}$ & Site order & Min. - max. & & $\begin{array}{c}\text { Sample } \\
\text { grain }(\mathrm{cm})\end{array}$ & $\mathrm{p}$ & Site order & Min. - max. \\
\hline $\begin{array}{l}\text { Number } \\
\text { of genera }\end{array}$ & 0.0001 & $\frac{81091}{42736} 5$ & $10.1-23.7$ & $\begin{array}{l}\text { Immobile } \\
\text { biological }\end{array}$ & $30 \times 60$ & 0.0108 & $8 \underline{1056974123}$ & $0.62-1.9$ \\
\hline $\begin{array}{l}\text { Shannon- } \\
\text { Wiener }\end{array}$ & 0.0001 & $\underline{841} \underline{9102} \underline{7635}$ & $1.4-2.6$ & Sediments & $30 \times 100$ & 0.0001 & $9 \underline{6213478105}$ & $1.5-2.8$ \\
\hline Evenness & 0.0001 & $\underline{418} \underline{79210563}$ & $0.5-0.9$ & Miscellaneous & $30 \times 60$ & 0.0108 & $8 \underline{1056974123}$ & $0.6-1.2$ \\
\hline Richness & 0.0001 & $\underline{89141027365}$ & $2.2-5.3$ & & & & & \\
\hline
\end{tabular}

direction of ecological relationships. Observations of habitat structure for these variables sampled at different spatial grains showed the same general pattern between sites, although differences in the $p$ values for the tests for different grain of the same variable provided some evidence that habitat structure varied with scale of sampling. Not surprisingly, the multivariate measures of habitat structure revealed the strongest differences between sites; these variables best accounted for habitat structure at the site scale based on the largest grain sampled $(30 \times 100 \mathrm{~cm})$.

\section{Relationships between habitat structure and macrobenthic diversity}

We developed regression models, based on measures of habitat structure, that explained 74 to $86 \%$ of the variance in macrobenthic diversity (Table 3). Water depth, averaged across transects at a site, was not important in explaining differences in macrobenthic diversity between sites. However, for each diversity index, both univariate and multivariate measures of habitat structure were important. The relative multivariate dispersion, was important for all indices of macrobenthic diversity, except number of genera. Slope estimates indicate that this factor was positively related to diversity. The mean Bray-Curtis dissimilarity was important for all diversity measures, but was negatively related to diversity. These 2 multivariate measures of within-site variation in habitat structure generally work in combination, with the mean Bray-Curtis dissimilarity restricting over-estimation of diversity by the relative multivariate dispersion at more complex sites. This suggests the possibility of a threshold effect of a threshold effect where biodiversity no longer increases with increasing habitat structure.

For all measures of biodiversity, sites with high average numbers of different habitat structural elements had high diversity. The type of habitat features that were important depended on the diversity index. All measures of diversity, except evenness, were related to number of different sedimentary features. However, all the measures of diversity were also related to either the number of different immobile biological features or the number of different miscellaneous features. The different elements of habitat structure had effects on diversity at different sample grains, although the most important sample grain for each element was consistent. Thus, the number of different sedimentary features was always important at a grain of $30 \times 100 \mathrm{~cm}$. Interestingly, the grain at which the number of different sedimentary features was most important was larger than that at which the number of different immobile biological features was most important. Nevertheless, the presence of habitat structure elements always had a positive effect on the 4 macrobenthic diversity indices.

The RELATE procedure demonstrated significant agreement in the pattern within the multivariate matrices describing the macrobenthic and habitat structure data (global Spearman's $\rho=0.212$ and 0.189 with $\mathrm{p}=$ 0.003 and 0.039 for the east-west and north-south directions, respectively). The stronger concordance running in the east-west direction indicated stronger effects across tidal flows. Overall, both data sets described complementary patterns, and thus measures of habitat structure derived from video analysis appear to be a good surrogate for estimating macrobenthic diversity. 
Table 3. Regression models based on habitat structure developed to explain variation in macrobenthic diversity between the 10 site samples in Kawau Bay. Grain of sampling used in the video counts is given

\begin{tabular}{|c|c|c|c|c|}
\hline Macrobenthic diversity & $\mathrm{r}^{2}$ & Factor & Parameter estimate & $\mathrm{p}$ \\
\hline \multirow{4}{*}{ Evenness } & 0.7510 & Intercept & 0.678903 & 0.0007 \\
\hline & & $\ln ($ immobile biological, $30 \times 60 \mathrm{~cm}$ ) & 0.435387 & 0.0081 \\
\hline & & Relative multivariate dispersion, $30 \times 100 \mathrm{~cm}$ & 0.561242 & 0.0504 \\
\hline & & Mean Bray-Curtis dissimilarity, $30 \times 100 \mathrm{~cm}$ & -0.012562 & 0.0148 \\
\hline \multirow[t]{5}{*}{ Shannon-Wiener } & 0.8265 & Intercept & 0.734187 & 0.3902 \\
\hline & & $\ln ($ miscellaneous, $30 \times 60 \mathrm{~cm})$ & 1.873924 & 0.0081 \\
\hline & & $\ln ($ sediment characteristics, $30 \times 100 \mathrm{~cm})$ & 1.423658 & 0.0785 \\
\hline & & Relative multivariate dispersion, $30 \times 100 \mathrm{~cm}$ & 2.049470 & 0.0624 \\
\hline & & Mean Bray-Curtis dissimilarity, $30 \times 100 \mathrm{~cm}$ & -0.044275 & 0.0203 \\
\hline \multirow[t]{5}{*}{ Richness } & 0.8626 & Intercept & 1.242798 & 0.4529 \\
\hline & & $\ln ($ miscellaneous, $30 \times 60 \mathrm{~cm}$ ) & 3.659516 & 0.0082 \\
\hline & & $\ln ($ sediment characteristics, $30 \times 100 \mathrm{~cm})$ & 3.852469 & 0.0284 \\
\hline & & Relative multivariate dispersion, $30 \times 100 \mathrm{~cm}$ & 2.907110 & 0.1437 \\
\hline & & Mean Bray-Curtis dissimilarity, $30 \times 100 \mathrm{~cm}$ & -0.074547 & 0.0344 \\
\hline \multirow[t]{4}{*}{$\ln$ (number of genera) } & 0.7372 & Intercept & 2.358474 & 0.0005 \\
\hline & & $\ln ($ immobile biological, $30 \times 60 \mathrm{~cm}$ ) & 0.609790 & 0.0196 \\
\hline & & $\ln ($ sediment characteristics, $30 \times 100 \mathrm{~cm})$ & 1.000411 & 0.0339 \\
\hline & & Mean Bray-Curtis dissimilarity, $30 \times 100 \mathrm{~cm}$ & -0.005818 & 0.1102 \\
\hline
\end{tabular}

\section{DISCUSSION}

The results support our prediction that there is a positive relationship between habitat structure and macrobenthic diversity in coastal soft-sediment habitats. Our sites spanned a range of habitats that differed both in sediment characteristics and the presence of a variety of epifauna. Our analysis implies that relatively low-density features creating small-scale structure on the seafloor (e.g., sponges $<2$; hydroids $<1$; horse mussels $<17$ individuals per $0.3 \mathrm{~m}^{2}$ ) can significantly influence macrobenthic diversity on the 100 to 1000 s of metres scale. Although there was variability in the strength and the exact parameters of relationships derived for the different diversity indices, our conclusions are consistent regardless of the index used.

The relative importance of physical and biological elements of habitat structure varied with spatial scale. We constrained our statistical models to include 1 sampling grain for each factor to prevent very strong covariation amongst variables affecting the consistency of our results. Our measures of habitat structure were divided into sedimentary, immobile biological and miscellaneous aspects. Across different measures of macrobenthic diversity, our results consistently suggest that small-scale macrofaunal biodiversity is affected directly or indirectly by immobile epifauna within an area of $0.18 \mathrm{~m}^{2}$, while the influence of sediment characteristics accumulates over $0.3 \mathrm{~m}^{2}$. The miscellaneous aspects were a combination of factors representing small-scale disturbance (e.g., ripples, mounds, feeding pits) and dead bivalve shells. Thus, this category also represents biogenic features. Sedimentary aspects were important for most measures of diversity, although not for evenness. Habitat structure immediately surrounding the macrofauna (i.e. within $30 \times$ $30 \mathrm{~cm}$ ) was never the most closely related factor. We were also able to include estimates of habitat structure calculated over larger scales by investigating withinsite variability using multivariate analysis. The relative multivariate dispersion and mean Bray-Curtis dissimilarity encapsulated changes in the elements defining habitat structure down each transect. These measures of within-site variability in habitat structure were always important in explaining the relationship between macrobenthic diversity and habitat structure, although their relative importance changed between diversity indices. Consistency in their relative importance was observed for all but number of genera. While the relative multivariate dispersion of habitat structure elements was always positively related to diversity, the estimate of mean within-site variability (represented by mean percent dissimilarity) always had negative slope parameter estimates. This restricted over-estimation of diversity by the relative multivariate dispersion at more structured sites and suggests the possibility of a threshold in the relationship between biodiversity and habitat structure.

Using the regression estimates for the different diversity indices, we determined how habitat structure 
affected macrofaunal diversity at individual sites. We demonstrated this with reference to evenness and richness. For example, Sites 4 and 8 both have moderate variability in within-site structure; thus our regression would predict medium evenness. They also both have medium to high numbers of different types of immobile biological features, which should increase the evenness values. However, Site 8 has higher mean withinsite dissimilarity and thus has a lower evenness. Similarly, Sites 8 and 9 exhibit the highest richness, even though Site 9 has a much lower variability of withinsite structure and fewer types of immobile biological features. However, Site 9 also has more types of sedimentary features and a lower mean within-site dissimilarity (both of which increase richness).

To best define the relationship between habitat structure, as measured by video, and macrofaunal diversity, we stratified our sampling to include as many samples from different habitats as possible. This was done at 2 different scales. Firstly, sites were chosen to reflect different levels of habitat structure generated by different features. For example, bare substratum could be mud or sand, but both represent a low level of structure. A higher level of structure would result from an area of horse mussel shells protruding from the sediment or from a mix of sand, diatom mats and sponges. Secondly, within-transect differences in habitat type were identified and samples were taken within each type. This second scale of sampling allowed us to investigate the importance of local variation in habitat structure (measured within $1 \mathrm{~m}$ of the core) in accounting for variation in macrobenthic diversity measured across sites ( $\mathrm{km}$ scale). Small-scale heterogeneity is often important in accounting for variations in density, biomass and diversity in marine benthic assemblages (e.g., Thrush 1991, Blanchard \& Bourget 1999). By including small-scale habitat structure, our sampling method increased the gradient of effect, and allowed the detection of a relationship with a minimum of samples at a variety of sites distributed over scales of kilometres.

The integration of small-scale variation into broader patterns is important because we might expect threshold effects and non-linearities in multi-species biotic and environmental processes that create biodiversity. For example, differences in density and species amongst a functionally similar group of bioturbators had different effects on biodiversity (Widdicombe \& Austen 1999). Cummings et al. (2001) demonstrate the potential for different responses of macrobenthic assemblages to the presence of a large epifaunal bivalve under a number of different physical regimes and local species pools. Regardless of the potential complexity of underlying processes, we found strong relationships between diversity and habitat structure using relatively simple measures of structure. Rather than emphasising the need to improve our understanding of small-scale variability to resolve the nature of factors affecting benthic community structure and function (i.e., biodiversity), we tried to scale-up and identify general patterns. We did this by summarising within-site patterns to avoid noise and be able to assess emergent patterns while still retaining information at the fine-scale resolution (Hewitt et al. 1998).

Our results also enabled us to assess the utility of using seafloor video images as a surrogate for direct estimates of macrobenthic diversity. The regression models relating macrobenthic diversity to habitat structure provide evidence that the video images were a good surrogate. However, we also carried out a direct comparison between the macrofaunal communities observed in each core with observations of the seafloor around the core samples. Unlike the habitat structure analyses, this analysis included abundances of the different features and also mobile features such as epibenthic predators and grazers. The 2 multivariate datasets were significantly related, indicating that seafloor video imagery could be used as a surrogate for direct measures of macrobenthic diversity. This has real value for developing rapid assessment strategies for soft-sediment habitats, particularly as video imagery of the seafloor can be carried out over large distances and at great depth. Recently, effort has been put into finding surrogates to increase our ability to rapidly assess large areas. Ward et al. (1999) found that habitat-level surrogates were useful for initial identification of marine reserves, while plant assemblages were poor surrogates for overall species richness. This is consistent with our results that emphasise elements of both biotic and physical heterogeneity and complexity. Being able to rapidly assess diversity at relatively fine resolutions would minimise the possibility of missing important diversity hot-spots in the landscape when mapping-unit resolution is too coarse (Stohlgren et al. 1997).

Our results have important implications for assessing the consequences to marine biodiversity of broad-scale disturbance events that remove epifauna and homogenise sediment characteristics. We found local variation in surficial sediment characteristics and the presence of other immobile features, many of which are biogenic, to be strongly related to diversity. As macrobenthic diversity makes a significant contribution to marine biodiversity (Gray 1997, Snelgrove 1999), our results suggest that relatively sparse elements of habitat structure can have important implications for resource management and conservation. Many types of broad-scale disturbance modify these features of soft-sediment habitat structure (Ellis et al. 2000). In particular, the disturbance and removal of epifauna 
and homogenisation of small-scale variability in sediment characteristics has been reported from studies of trawling and dredging (Mayer et al. 1991, Dayton et al. 1995, Jennings \& Kaiser 1998, Thrush et al. 1998, Auster \& Langton 1999). Removal of habitat structure can, therefore, be anticipated to not only decrease macrobenthic diversity but also the more general biodiversity of the marine system. Given the spatial extent of marine soft-sediment habitats and the extent to which these habitats are subject to intensive bottomfishing (FAO 1997), creating marine protected areas is unlikely to be sufficient to maintain and enhance biodiversity. Integrated and spatially explicit schemes that actively manage marine habitats are necessary (Ray 1996, Gray 1997, Auster \& Langton 1999).

Acknowledgements. This research was supported by FRST CO1804 and NIWA-NSOF.

\section{LITERATURE CITED}

Auster PJ, Langton RW (1999) The effects of fishing on fish habitat. Am Fish Soc Symp 22:150-187

Bell SB, McCoy ED, Mushinsky HR (1991) Habitat structure, the physical arrangement of objects in space. Chapman \& Hall, London

Bengtsson J, Jones H, Setala H (1997) The value of biodiversity. Trends Ecol Evol 12:334-336

Blanchard D, Bourget E (1999) Scales of coastal heterogeneity: influence on intertidal community structure. Mar Ecol Prog Ser 179:163-173

Clarke KR (1993) Non-parametric multivariate analyses of changes in community structure. Aust J Ecol 18:117-143

Clarke KR, Warwick RM (1994) Changes in marine communities: an approach to statistical analysis and interpretation. Natural Environment Research Council, Swindon

Coleman N, Gason ASH, Poore GCB (1997) High species richness in the shallow marine waters of south east Australia. Mar Ecol Prog Ser 154:17-26

Conover WJ (1980) Practical nonparametric statistics. John Wiley \& Sons, New York

Costanza R, d'Arge R, de Groot R, Farber S and 9 others (1997) The value of the world's ecosystem services and natural capital. Nature 387:253-260

Cranfield HJ, Michael KP, Doonan IJ (1999) Changes in the distribution of epifaunal reefs and oysters during 130 years of dredging for oysters in Foveaux Strait, southern New Zealand. Aquat Conserv Mar Freshw Ecosyst 9:461-483

Crawley MJ (1993) GLIM for ecologists. Blackwell Scientific Publications, Oxford

Cummings VJ, Thrush SF, Hewitt JE, Funnell GA (2001) Variable effect of a large suspension-feeding bivalve on infauna: experimenting in a complex system. Mar Ecol Prog Ser 209:159-175

Dame RF (1993) Bivalve filter feeders in estuarine and coastal ecosystem processes. NATO ASI Ser 2.33

Dayton PK, Tegner MJ (1984) The importance of scale in community ecology: a kelp forest example with terrestrial analogs. In: Price PW, Slobodchikoff CN, Gaud WS (eds) A new ecology: novel approaches to interactive systems. John Wiley \& Sons, New York, p 457-483
Dayton PK, Thrush SF, Agardy TM, Hofman RJ (1995) Environmental effects of fishing. Aquat Conserv Mar Freshw Ecosyst 5:205-232

Dayton PK, Tegner MJ, Edwards PB, Riser KL (1998) Sliding baselines, ghosts, and reduced expectations in kelp forest communities. Ecol Appl 8:309-322

Ellis J, Norkko A, Thrush S (2000) Broad scale disturbance of intertidal and shallow sublittoral soft sediment habitats: effects on benthic macrofauna. J Aquat Ecosyst Stress Recovery 7:57-74

Etter RJ, Grassle F (1992) Patterns of species diversity in the deep sea as a function of sediment particle size diversity. Nature 360:576-578

FAO (1997) Review of the state of the world fishery resources: marine fisheries. FAO Fish Circ 920 FIRM/C920

Fisheries Act (1996) New Zealand Parliament Laws and Statutes. Government Printer, Wellington, NZ

Freckman DW, Blackburn TH, Bussaard L, Hutchings P, Palmer MA, Snelgrove PVR (1997) Linking biodiversity and ecosystem functioning of soils and sediments. Ambio 26:556-562

Gower JC (1987) Introduction to ordination techniques. In: Legendre P, Legendre L (eds) Developments in numerical ecology. Springer-Verlag, Berlin, p 3-64

Graf G, Rosenberg R (1997) Bioresuspension and biodeposition: a review. J Mar Syst 11:269-278

Gray JS (1997) Marine biodiversity: patterns, threats and conservation needs. Biodiv Conserv 6:153-175

Gray JS (2000) The measurement of marine species diversity, with an application to the benthic fauna of the Norwegian continental shelf. J Exp Mar Biol Ecol 250:23-50

Gray JS, Poore GCB, Ugland KI, Wilson RS, Olsgard F, Johannessen O (1997) Coastal and deep-sea benthic diversities compared. Mar Ecol Prog Ser 159:97-103

Green MO, Hewitt JE, Thrush SF (1998) Seabed drag coefficients over natural beds of horse mussels (Atrina zelandica). J Mar Res 56:613-637

Hammer MA, Jansson AJB (1993) Diversity change and sustainability: implications for fisheries. Ambio 22:97-105

Hewitt JE, Thrush SF, Cummings VJ, Turner SJ (1998) The effect of changing sampling scales on our ability to detect effects of large-scale processes on communities. J Exp Mar Biol Ecol 227:251-264

Hill MO (1973) Diversity and evenness: a unifying notation and its consequences. Ecology 54:427-432

Huston MA (1997) Hidden treatments in ecological experiments: re-evaluating the ecosystem function of biodiversity. Oecologia 110:449-460

Irlandi EA, Ambrose WG Jr, Orlando BA (1995) Landscape ecology and the marine environment: how spatial configuration of seagrass habitat influences growth and survival of bay scallop. Oikos 72:307-313

Jennings S, Kaiser MJ (1998) The effects of fishing on marine ecosystems. Adv Mar Biol 34:203-314

Koenig CC, Coleman FC, Grimes CB, Fizhugh GR and 3 others (2000) Protection of fish spawning habitat for the conservation of warm temperate reef fish fisheries of shelf-edge reefs of Florida. Bull Mar Sci 66:593-616

Kolasa J, Rollo CD (1991) The heterogeneity of heterogeneity: a glossary. In: Kolasa J, Pickett STA (eds) Ecological heterogeneity. Springer-Verlag, Berlin, p 1-23

Krebs CJ (1989) Ecological methodology. Harper \& Row, New York

Legendre P, Legendre L (1998) Numerical ecology. Elsevier, Amsterdam

Luckenbach MW (1987) Effects of adult infauna on new recruits: implications for the role of biogenic refuges. J Exp Mar Biol Ecol 105:197-206 
Mayer LM, Schick DF, Findlay RH, Rice DL (1991) Effects of commercial dragging on sedimentary organic matter. Mar Environ Res 31:249-261

McCoy ED, Bell SS (1991) Habitat structure: the evolution and diversification of a complex topic. In: Bell SB, McCoy ED, Mushinsky HR (eds) Habitat structure, the physical arrangement of objects in space. Chapman \& Hall, London, p 3-17

McCullagh P, Nelder JA (1989) Generalised linear models. Chapman \& Hall, London

Norse EA (1993) Global marine biodiversity strategy; building conservation into decision making. Centre for Marine Conservation, Washington, DC

Peet RK (1975) Relative diversity indices. Ecology 56:496-498 Pielou EC (1975) Ecological diversity. John Wiley \& Sons, New York

Ray GC (1996) Coastal-marine discontinuities and synergisms: implications for biodiversity conservation. Biodiv Conserv 5:1095-1108

Reise K (1981) High abundance of small zoobenthos around biogenic structures in tidal sediments of the Wadden Sea. Helgol Meeresunters 34:413-425

Rhoads DC, Aller RC, Goldhaber M (1977) The influence of colonising benthos on physical properties and chemical diagenesis of the estuarine seafloor. In: Coull BC (ed) Ecology of marine benthos. University of South Carolina Press, South Carolina, p 113-138

Robbins BD, Bell SS (1994) Seagrass landscapes: a terrestrial approach to the marine subtidal environment. Trends Ecol Evol 9:301-304

Schlapfer F, Schmid B (1999) Ecosystem effects of biodiversity: a classification of hypotheses and exploration of empirical results. Ecol Appl 9:893-912

Schneider DC, Gagnon JM, Gilkinson KD (1987) Patchiness of epibenthic megafauna on the outer Grand Banks of Newfoundland. Mar Ecol Prog Ser 39:1-13

Snelgrove PVR (1999) Getting to the bottom of marine biodiversity: sedimentary habitats - ocean bottoms are the most widespread habitat on Earth and support high biodiversity and key ecosystem services. BioScience 49: 129-138

Stohlgren TJ, Chong GW, Kalkhan MA, Schell LD (1997)

Editorial responsibility: John Gray (Contributing Editor), Oslo, Norway
Multiscale sampling of plant diversity: effects of minimum mapping unit size. Ecol Appl 7:1064-1074

Thrush SF (1991) Spatial patterns in soft-bottom communities. Trends Ecol Evol 6:75-79

Thrush SF, Cummings VJ, Dayton PK, Ford R and 11 others (1997a) Matching the outcome of small-scale density manipulation experiments with larger scale patterns: an example of bivalve adult/juvenile interactions. J Exp Mar Biol Ecol 216:153-170

Thrush SF, Schneider DC, Legendre P, Whitlatch RB and 8 others (1997b) Scaling-up from experiments to complex ecological systems: where to next? J Exp Mar Biol Ecol 216:243-254

Thrush SF, Hewitt JE, Cummings VJ, Dayton PK and 6 others (1998) Disturbance of the marine benthic habitat by commercial fishing: impacts at the scale of the fishery. Ecol Appl 8:866-879

Tokeshi M (1999) Species coexistence ecological and evolutionary perspectives. Blackwell, Oxford

United Nations Environment Programme (1992) Convention on biological diversity. United Nations (Environment Programme), Rio de Janeiro

van Blaricom GR (1982) Experimental analysis of structural regulation in a marine sand community exposed to oceanic swell. Ecol Monogr 52:283-305

Ward TJ, Vanderklift MA, Nicholls AO, Kenchington RA (1999) Selecting marine reserves using habitats and species assemblages as surrogates for biological diversity. Ecol Appl 9:691-698

Warwick RM, Clarke KR (1993) Increased variability as a symptom of stress in marine communities. J Exp Mar Biol Ecol 172:215-226

Widdicombe S, Austen MC (1999) Mesocosm investigation into the effects of bioturbation on the diversity and structure of a subtidal macrobenthic community. Mar Ecol Prog Ser 189:181-193

Woodin SA (1983) Biotic interactions in recent marine sedimentary environments. In: Tevesz MJS, McCall PL (eds) Biotic interactions in recent and fossil benthic communities. Plenum Press, New York, p 3-38

Zar JH (1984) Biostatistical analysis, 2nd edn. Prentice-Hall, Englewood Cliffs, NJ

Submitted: September 7, 2000; Accepted: February 14, 2001 Proofs received from author(s): October 2, 2001 